\title{
The effect of the Appleton model on the acquisition of syntactic concepts among students of the College of Administration and Economy, Department of Industrial Management
}

\author{
Dr. Taghreed Fadhil Abbas, Assistant Professor, University of Baghdad /College of Management and \\ Economics
}

Rafid Sabah al - Tamimi, Assistant Professor, University of Baghdad /College of Management and Economics rafid0074@coadec.uobaghdad.edu.iq

\begin{abstract}
The teaching Arabic language is marred by many deficiencies because teachers are focusing on a purely theoretical method. Therefore, there is an urgent need to employ modern teaching methods. Accordingly, this investigationaimedat identifying the effect of the Appleton model onstudents' acquisition of Arabic syntacticconcepts. The research specimenconsisted of the first-stage students in the Department of Industrial Management,College of Administration and Economy, Baghdad University for the academic year 2019-2020, the first semester. It was concluded thatthe Appleton model had an effect on the acquisition of Arabic syntactic concepts compared to the conventional method.Based on the research findings, the researchers suggested some recommendations.
\end{abstract}

Article Received: 10 August 2020, Revised: 25 October 2020, Accepted: 18 November 2020

- What is the effect of the Appleton model onstudents' acquisition of syntactic conceptsatCollegeof Administration and Economy, Department of Industrial Management?

\section{Research Objective}

This investigationaimed at identifying the effect of the Appleton model on students' acquisition of syntacticconcepts at College of Administration and Economy, Department of Industrial Management.

\section{Research Hypotheses}

For achieving research objective, three hypotheses were developedas follows:

1. There is a statistically significant variance between the average scores of the experimental grouping students who were taught utilizing the Appleton method and those of the control grouping who were taught utilizing the conventional method in the post-test at the significance level (0.05).

2. There is a statistically significant variance at the significance level (0.05) in the average variances between the scores of the pre- and post-tests of the acquisition of syntactic concepts among the students of the experimental grouping who were taughtutilizing the Appleton method.

3. There is no statistically significant variance at the significance level (0.05) in the average of variances between the scores of the pre- and post-tests of the acquisition of syntactic concepts among

\section{Introduction}

\section{Research Problem}

The teaching and learning process of Arabic language entails various difficulties. Its teaching is marred by manydeficiencies because universities and schools have focused on a purely theoretical method, impeding its development. Thelow levels of students in the Arabic language demonstratesthe effects of those difficulties. This is attributed to several reasons including its syntactic structure and the various and complex topics with severalunits and details that require further explanation and analysis. In addition, the Arabic language textbook may be a brief book that is not commensurate with the level of mental capacity of the students as well as the absence of exercises that develop theirskill of expression (Al-Khalidi, 1993). Consequently, there is an urgent need to employ modern teaching methods and models. The conventional methods are no longer sufficient to achieve the scientific objectives of teaching the Arabic language, as emphasized by the curriculum in Iraq, represented by the acquisition of basic syntactic concepts and the improvement of their tendencies. Hence,the problem of research lies in finding a teaching model suitable for the educational environment in Iraq and achieve effective learning that makes students participating in the educational process and improves their achievement, as well as increasing their desire to acquire syntactic concepts. Based on the above, the problem of research is formed in the following question: 
1. The importance of Arabic language as an essential material in educating the individual and making him a good citizen.

2. The importance of the Appleton model and its steps that make the learner the focus of the educational process, motivate learners to think and learn to think and employ effective educational activities, and keep them away from the conventional method that focuses on memorization.

3. The importance of concepts as the basic elements of every subject.

4. The university stage is an important stage for the formation of the individual's personality who understands his role in society, his rights and duties. Thus, s/he should be properly directed at this stage as it is the stage of preparing the learner.

\section{Research Scope}

The current research wasconfined toteaching the Arabic language for thefirst-stage students in Department of Industrial Management, College of Administration and Economy, University of Baghdad, of the academic year 2019-2020, First Semester.

\section{Definition of Terms}

\section{The Appleton Model}

a. It refers to a model with four characteristics reflecting the main features of any constructive model, namely, existing ideas, processing information, seekinginformation and the social context (al-Muhaysin, 2007).

b. It isa model that is based on the sources of constructive theory, particularly Piaget's vision of accommodation and imbalance, and the opinions of Klaxton and Howard on the adaptation between past and subsequent experiences within the individual's cognitive system in particularthe school experiences that are based on Vygotsky's social theory, making the model effective in the constructive teaching (Attia, 2015).

c. Al-Muhaysin's (2007) conceptual definition is adopted in this investigation. As for the operational definition, it is the model used in all of its stages in order for the students to acquire syntactic concepts.

\section{Acquisition of the Concept}

a. It is defined as avisualization of situations, values, attitudesor behaviors associated with the Arabic language and expressed by word, term or phrase(As-Suwaidi, 1992). As for al-Matroudi (2009), it refers toa term or phrase that expresses a the students of the control grouping who were taughtutilizing the conventional method.

\section{Research Significance}

Language is one of the most prominent human phenomena and characteristics. It creates thought and culture in man and helps in the expression of inner feelings.Language, human and civilization are elements interacting with every other since the emergence of man on earth. The more the individual's competence oflanguage skills, the more his interactionwith all elements of society with awareness and high skill. Therefore, any society concerned with all methods of language improvement leads its members towards developing levels of creativity and innovation and achieving success in all areas of sophistication and prosperity (an-Naqah, 1995). The Arabic language is the sacred link that binds the people of the Arab nation.It is the language of religion and faith, and hence it has been able to accommodate all civilizations, as well as the Arabic statement is the linguistic manifestation of the divine miracle embodied in the Holy Qur'an (az-Zubay, 2009).

Modern teaching strategies are important in mastering the scientific material or the cognitive structure of the curriculum content and achieving its objectives properly, actively integrating into the learning process, as well as developing multiple affective aspects like curiosity, the positive attitude towards learning and the skills of both teachers and students. This in turn allowsevery learner to practice and master these skills individually (Shaheen, 2010). Appleton is an educational theorist at the Faculty of Education, Central Queensland University, Australia.Through his model, Appleton has tried tohighlight and identifythe overlapping factors and find the cognitivescaffolding between theory and practice, especially between students and teachers and among the students themselves. This would make this model effective in constructive teaching (AlAssadi \&Al-Massoudi, 2015).Scaffolding refers to temporal support for learners to enable them to rely on self-learning. It consists of activities, cues and information provided by the teacher to help and encourage students to reachthe desired solution that they are looking for or intended to reach (Nwosu\&Azih, 2011).As Bruner and Vygotsky call it, scaffolding is a process helping the learner to solve a particular problem that is beyond his cognitive abilities, supported by a teacher or a more advanced experienced peers(Zambrano\&Noriega, 2011).

Accordingly, the importance of the current research is illustrated as follows: 
learner to seek informationto find a solution,which stimulates the memory (Attia, 2015).

\section{c. Seeking Information}

At this stage, learners who could not provide complete answers about the situation need scaffolding, which is represented bycues and small bits of information that helps them to find the complete answers through research and exploration. Thus, the role of the teacher at this stage represents the supporting promoter who stimulates them to seek the answer by providing learners with the keys to the search. This process is done utilizing various methods including the practical presentations offered by the teacher, or the teacher's ideaslike educational materials available in the learning environment, and the ideas of other learners and peers. These sources are used based on the social context of teaching and learning viewed by the constructivism (Zayer, 2014).

\section{The Concept: An Introduction}

The concepts are the basis of knowledge, which become more importantcurrentlydue tothe explosion of knowledge and the expansion of its branches. Consequently, the teacher becomes focusing on helping students understand and realize the conceptual and logical structure of the material while leaving the details (Mara'i \& Muhammad, 2009). In the structure of the cognitive system, the concept follows the facts; therefore, they differ in the following characteristics as indicated by Ibrahim (2009):

- Discrimination and classification: the concept distinguishes and classifiesthings according to common factors.

- Symbolism: the conceptsymbolizes a characteristic or a set of abstract characteristics.

- Generalization: the concept iscomprehensiveas it applies to varioussituationsand attitudes.

Accordingly, the concept is a mere mental conception that is named or symbolizedto showspecificphenomena or events, sharing one or several attributes (Ibrahim, 2009).

\section{The Acquisition of Concepts}

The process of concept acquisition is amongthe main objectives sought to be achieved byteachers through variouseducational situations for all stages (Al-Jubouri, 2001). It representsa significantpart of the learning process in the classroom. Teachers regularlyteachnew concepts for students utilizing variousmethods of presentation. Thisvariation may occur even when presenting two various concepts for one category (Abu Zeina, 2010). There are several factors associated withthe teacher's role in the students' acquisition of concept including: common characteristic(s) involved in varioussituations, events or syntactic concepts.

b. The operationaldefinition of the acquisition of syntacticconcepts refers to a set of meanings, vocabulary and terms expressed bywords, sentences or phrases so that the student can define and apply them in various learning situations.

2. Theoretical Framework and Literature Review

\section{The Appleton Model: An Overview}

Ken Appleton has developed this model in 1997. It is based on the constructive theory, particularly Piaget's vision of accommodation and imbalance and the opinions of Klaxton and Howard on the adaptation between past and subsequent experiences within the individual's cognitive system in particular the school experiences in the social context that is emphasized by Vygotsky(Attia, 2015).It is one of the applications of contemporary theories (constructive theory) in learning. This theory is defined as a process of receivingthat includes the reconstruction of learners for new meanings within the context of their current knowledge with their previous experiences and learning environment, representing both reallife experiences and previous information, as well as the atmosphere of learning the basic aspects of constructive theory (Zaytoun, 2007).

\section{Stages of the Appleton Model}

\section{a. Existing Ideas}

This stage represents the starting point in the constructive learning, which considers that new learning is based on previous knowledge through diagnosing and sorting the ideas of learners before starting to display the content (Calik\&Pasayas, 2006).At this stage, various methods such as schemata, interviews or exploratory questions are used to sort the learner's ideas. In the light of the learner's answers, experiences are categorized into ideas and cognitive systems that can be recalled when interpreting the events and new experiences presented to them. Then, a comprehensive idea is given on the learner's vision of the world and interpretation ofits events and his/ her behaviorin it (Al-Assadi \&Al-Massoudi, 2015).

\section{b. Processing Information}

At this stage, the learner attempts to identify the properexplanation forconstructing meaning about the new information.There are three possibilities, either: a new form of information is formed that fits perfectly with the existing idea and satisfies the student,an approximate fit, or cognitive conflict (Qarni, 2011). The cognitive conflict and the lack of accommodation between the learner's existingknowledge and new learning lead the 
the experimental groupingstudents who were taught according to the Appleton model achieved higher scores compared to the control groupingstudents who were taught utilizing the conventional method in relation to the acquisition of syntactic concepts.

Shnawa and Abdul-Ameer (2018) aimed at finding out the effectiveness of the Appleton model in achievement and deductive thinking among students of the second intermediate grade in the subject of history. They employed theexperimental design ofthe partial controlwith two equal groupings. The research specimenincluded (50) female students randomly selected and divided into (25) students forevery grouping. The two groupings were statistically equal in the variables of (intelligence, age, qualification of parents, previous achievement of history and deductive thinking).As for the research tools, an achievement test was designed consisting of (40) multiple-choice items, a deductive thinking test consisting of (30) items after determining their validity and reliability. The findings of the research showed the superiority of the experimental grouping in achievement and deductive thinking.

\section{Research Method}

\section{The Experimental Design}

The design of the experimental and control groupings was adopted with applying the pre- and post-test,taking into accountthe research objectivesand hypotheses. The presence of the control groupingincreases the accuracy of findings. Hence, the time factor and the teaching methodmay affect the level of accuracy.
1. Identifyingthe requiredmotivationsand report the learner about them.

2. Identifyingthe preferredanswersand report the learner about them.

3. Identifyingthe appropriate strategies and report the learner about them.

4. Preparingthe requiredinformation for the concept.

5. Preparingstudents to recall the correctinformation.

6. Increasingthe motivation level for the learner (Al-Yamani, 2009).

\section{Previous Studies}

Al-Lami and Amir (2017) aimed at identifying the impact of the Appleton model on acquiring syntactic concepts for students in the fourth preparatory grade.To achieve this objective,the researchers conducted an experiment that lasted for two months. Theyrandomly selected Al-Fayhaa High School for Boys to conduct the experiment. The researchspecimenincluded(68) students, distributedto twogroupings, namely, experimental and control witha total of (34) students for each. The two groupings were equal in the variables (age, intelligence quotient, scores of first term exam and qualification of parents). The researchers adopted an experimental design ofthe partial control in the pretest of the two groupings. The extraneous variable was defined to reduce the impact of experimental procedures and applied experience in the second semester of the academic year (20152016). After completing the experiment, its findings were statistically analyzed utilizing a T-test for two independentspecimens. The findings showed that

Table 1: The research groupings

\begin{tabular}{|l|l|l|l|}
\hline Experimental grouping & Pre-test & The independent variable (educational program) & Post-test \\
\hline Control grouping & Pre-test & Did not experience the independent variable & Post-test \\
\hline
\end{tabular}

distributed to two groupings: experimental with (38) students and the control with (39) students after excluding the students who failed.

\section{The Equivalence of Research Groupings}

Before conductingthe experiment, the twogroupings were equalized statistically in certainvariables that could have aneffect on the experimentvalidity. These variables were:

a. Student'sage determined in months

\section{The Research Community and Specimen}

The research community represented the students selected fromCollege of Administration and Economy at Baghdad University for the academic year 2019-2020.Concerning the specimen, it was selected from thefirst stage, Department of Industrial Management during the first semester.The pre-test (acquisition of syntactic concepts) was applied to all students, who were (77)male and female students, and then they were

Table 2: Findings of the $T$-test for the average age between the researchgroupings

\begin{tabular}{|l|l|l|l|l|l|l|}
\hline Grouping & Number & Arith. Mean & S.D & \multicolumn{2}{l|}{ T-value } & $\begin{array}{l}\text { Significance } \\
\text { level (0.05) }\end{array}$ \\
\cline { 1 - 4 } & & & & Determined & Tabulated & \\
\hline Experimental & 38 & 243.8684 & 0.34257 & \multirow{2}{*}{0.854} & 2.045 & No variances \\
\hline Control & 39 & 243.7949 & 0.40907 & & & \\
\hline
\end{tabular}

Standard deviation $=$ S.D, Arithmetic mean $=$ Arith. Mean 
are found in the average age between the two groupings.

b. Scores of grammar acquisition test

Table 3: Findings of the T-test for the average scores in the pre-test between the research groupings

\begin{tabular}{|l|l|l|l|l|l|l|}
\hline Grouping & Number & Arith. Mean & S.D & \multicolumn{2}{|l|}{ T-value } & $\begin{array}{l}\text { Significance } \\
\text { level (0.05) }\end{array}$ \\
\cline { 4 - 7 } & & & & Determined & Tabulated & \\
\hline Experimental & 38 & 17.8684 & 0.34257 & 0.572 & 2.045 & No variances \\
\hline Control & 39 & 17.8205 & 0.38878 & & & \\
\hline
\end{tabular}

researchspecimen. Every correct question got one mark. The findings showed thatthe arithmetic mean of the experimental groupingwas (27.9737), while that of the control groupingwas (27.8974). By employing the T-test for two independent specimens, no statistically significant variancewas found at the significance level (0.05).Hence, the determined T-value (1.356) waslowercomparison with the tabulated value (2.38) withafreedom degree (75). Therefore, the two groupings were equalized in this variable, as clarified in table (4).
Table (2) demonstrates that the determined T-value (0.854) is lower comparison withthe tabulated value (2.045), showing that no significantvariances
Based on findings clarified in table (3), the determined T-value (0.572) is lower comparison with the tabulated value (2.045). Accordingly, no statistically significant variances are found in the level of syntactic concepts acquisition between the researchgroupings. Thus, the two groupings were equalized in this variable.

\section{c. Intelligence test}

Raven intelligence test was employed because it wasapplied tothe Iraqi environment.The test$$
\text { equatized in this variable, as clarified in table (4). }
$$
consisted of (60)questions, distributed to the
Table 4:Findings of the T-test for the average scores of intelligencein the pre-test between the twogroupings

\begin{tabular}{|l|l|l|l|l|l|l|}
\hline Grouping & Number & Arith. Mean & S.D & \multicolumn{2}{|l|}{ T-value } & $\begin{array}{l}\text { Significance } \\
\text { level (0.05) }\end{array}$ \\
\cline { 5 - 6 } & & & & Determined & Tabulated & \\
\hline Experimental & 38 & 27.9737 & 0.16222 & \multirow{2}{*}{1.356} & 2.045 & No variances \\
\hline Control & 39 & 27.8974 & 0.30735 & & & \\
\hline
\end{tabular}

wasdesignedon the basis of educational content and the three levels of concepts (definition, discrimination and generalization).

\section{Formulation of the Tests Items}

The objective itemswere adopted for beingcharacterized by validity, reliabilityand comprehensiveness. They were designed based on scientific criteria. They covered theinvestigation material and its objectives. The researchers selected multiple-choice test because it is commonly usedas well as reducingthe guessing factor. This test measures the three levels of acquisition of the concept through (35) items.

\section{Preparation of the Answer Instructions}

The answer instructions were formed toreportthe learners how to answer and the time specifiedfor it.The time taken to answer the test items was $(39,567)$ minutes.

\section{Instructions of the Test Correction}

A specimen ofanswer to the test items was made. Every correct answergot (1) mark and the incorrect answer got (0). The unanswered items and those with more comparison withone choice were treated he

\section{.}


intotwogroupings, one for the highest scores and the other for the lowest scores. The percentage of scores in these twogroupings is preferably to be $27 \%$ of the total scores, providing the best possible size and differentiation. The coefficient of difficulty was revealed forselectingthe items with the appropriate difficulty and deleting the itemsthat are very easy/ difficult.The findings showed that the coefficient of Difficultyrangedbetween (0.30$0.80)$, as shown in table (5). as wrong. The highestscore received by students was (35).

\section{Analysis of the Test Items}

\section{a. Statistical Analysis of Test Items}

The itemswere analyzed to improve the test quality by identifying and rewritingweak items and excluding the invalid ones utilizing the coefficients of difficulty and discrimination. In order to achieve this purpose,these procedures were followed: correct the answers of students;arrange the scoresin descending order;and dividethe students

Table 5: The coefficient of Difficulty for the items of the acquisition of concepts test

\begin{tabular}{|l|l|l|l|l|l|l|l|}
\hline No. & $\begin{array}{l}\text { Coefficient of } \\
\text { Difficulty }\end{array}$ & No. & $\begin{array}{l}\text { Coefficient of } \\
\text { Difficulty }\end{array}$ & No. & $\begin{array}{l}\text { Coefficient of } \\
\text { Difficulty }\end{array}$ & $\begin{array}{l}\text { Noefficient of } \\
\text { Difficulty }\end{array}$ \\
\hline 1 & 0.37 & 10 & 0.33 & 19 & 0.34 & 28 & 0.30 \\
\hline 2 & 0.33 & 11 & 0.31 & 20 & 0.34 & 29 & 0.43 \\
\hline 3 & 0.36 & 12 & 0.32 & 21 & 0.34 & 30 & 0.43 \\
\hline 4 & 0.38 & 13 & 0.38 & 22 & 0.80 & 31 & 0.49 \\
\hline 5 & 0.39 & 14 & 0.33 & 23 & 0.39 & 32 & 0.45 \\
\hline 6 & 0.37 & 15 & 0.49 & 24 & 0.57 & 33 & 0.38 \\
\hline 7 & 0.37 & 16 & 0.48 & 25 & 0.39 & 34 & 0.41 \\
\hline 8 & 0.35 & 17 & 0.47 & 26 & 0.31 & 35 & 0.30 \\
\hline 9 & 0.32 & 18 & 0.37 & 27 & 0.64 & & \\
\cline { 1 - 5 } & &
\end{tabular}

who do not have the measured feature or do not know the correct answer for every item of the test. After applying the equation of the coefficient of discrimination, all the values were greater comparison with (0.30), as clarified in table (6).

Bloom indicated that if the difficulty of testitems is between (0.20-0.80), the test is good. The coefficient of discrimination of items means the capacity of item to distinguish the individual variances between respondents who have the measured feature or know the answer and those

Table 6: The coefficient of discrimination for the items of the acquisition of concepts test

\begin{tabular}{|l|l|l|l|l|l|l|l|}
\hline No. & $\begin{array}{l}\text { Coefficient of } \\
\text { discrimination }\end{array}$ & No. & $\begin{array}{l}\text { Coefficient of } \\
\text { discrimination }\end{array}$ & No. & $\begin{array}{l}\text { Coefficient of } \\
\text { discrimination }\end{array}$ & No. & $\begin{array}{l}\text { Coefficient of } \\
\text { discrimination }\end{array}$ \\
\hline 1 & 0,60 & 10 & 0,50 & 19 & 0,47 & 28 & 0,40 \\
\hline 2 & 0,59 & 11 & 0,49 & 20 & 0,46 & 29 & 0,37 \\
\hline 3 & 0,61 & 12 & 0,49 & 21 & 0,59 & 30 & 0,40 \\
\hline 4 & 0,58 & 13 & 0,38 & 22 & 0,58 & 31 & 0,39 \\
\hline 5 & 0,55 & 14 & 0,42 & 23 & 0,57 & 32 & 0,38 \\
\hline 6 & 0,54 & 15 & 0,44 & 24 & 0,67 & 33 & 0,45 \\
\hline 7 & 0,58 & 16 & 0,43 & 25 & 0,46 & 34 & 0,39 \\
\hline 8 & 0,49 & 17 & 0,42 & 26 & 0,49 & 35 & 0,50 \\
\hline 9 & 0,59 & 18 & 0,43 & 27 & 0,48 & & \\
\cline { 1 - 4 } & & & &
\end{tabular}

items were kept because of their Based on findings presented in table (6), all values discriminativepower among students.

\section{b. The Validity of Test} withEbil's standard, who indicatedthat the item is well discriminated if the power of its discriminationis (0.30) and above. Accordingly, all 
week. The teaching process continued toMonday, 27/1/2020.

- The Appleton strategy was applied to the experimental grouping, and the conventionalprocesswas applied to the control grouping.

- The syntactic concept acquisition test was applied to the twogroupings simultaneously on Thursday, 30 January 2020.

e. Statistical Tools

- Pearson Correlation Coefficient: to find the test reliabilityutilizing the retest method.

- The Coefficient of Difficulty: to determinethe difficulty of the test items. toidentifythe discriminativepower of the test items.

- T-Test for Two Independent Specimens: to determineequivalence between the two groupings in variables in addition totest hypotheses.

\section{Findings and Discussion}

a. The First Hypothesis

By comparing findings of the post-test, the experimental groupinggot an arithmetic mean (32.9474) with a S.D (0.22629), while the control groupinggot(18.0513) with a S.D (0.22346).By employingthe T-Test for two independent specimens for determining the significantvariances between these means, a statistically significant variance was found between the two groupings as shown in table (7).
- The Coefficient of discrimination:

Facevalidityrepresents one of the measures necessary for extractingthe coefficient of the test validity.Hence, the test itemswere presented to a grouping of experts withconsideringtheir opinions on the adequacy of items tothe feature to be measured.Inthisresearch, the test itemswere presented to (10) experts and specialists to determine their opinions on the validity of the items. The experts agreed on the entire test items by $80-100 \%$.

\section{c. The Reliabilityof Test}

The retesttechnique is one of the most important methods employed forcalculating reliabilitydue toprovidinginformation on the findings consistency by having a time interval between the test and retest. It is indicated that time intervalbetween the two tests should not be long so that the students learn new information or forget informationthey havelearnt, nor should be short so that they remember the answers of the first test.Therefore, the duration should range between (10-20) days depending on the student's age and the number of test items.Thus, the researchers retested (35) students within (15) days between the two tests. Utilizing Pearson correlation coefficient,the reliabilityof test was (0.88),representing a high coefficient of reliability.

\section{d. Application of the Experiment}

The experiment was conducted based on the following steps:

- It was applied to the research specimen on Wednesday, 27/11/2019.Every groupingwas taught for (2) hours per

Table 7: T-test findings for two independent specimens of the concept acquisition post-test

\begin{tabular}{|c|c|c|c|c|c|c|c|}
\hline \multirow[t]{2}{*}{ Grouping } & \multirow[t]{2}{*}{ Number } & \multirow[t]{2}{*}{ Arith. Mean } & \multirow[t]{2}{*}{ S.D } & \multirow{2}{*}{$\begin{array}{l}\text { Freedom } \\
\text { degree }\end{array}$} & \multicolumn{2}{|l|}{ T-value } & \multirow{2}{*}{$\begin{array}{l}\text { Significance } \\
\text { level }\end{array}$} \\
\hline & & & & & Determined & Tabulated & \\
\hline Experimental & 38 & 32.9474 & 0.22629 & \multirow[t]{2}{*}{75} & \multirow[t]{2}{*}{290.628} & \multirow[t]{2}{*}{2.045} & \multirow[t]{2}{*}{0.05} \\
\hline Control & 39 & 18.0513 & 0.22346 & & & & \\
\hline
\end{tabular}

To provethis hypothesis, the T-Test was applied to two interrelated specimens to determine if there is an acquisition ofsyntactic concepts among students of the experimental groupingwho were taught utilizing the Appleton model. The arithmetic meanof the post-test was (32.9474) with a S.D of (0.22629) and that of the pre-test was (17.8684) with a S.D of (0.34257), as clarified in table (8).
Table (7) demonstrates that the determined T-value $(290,628)$ is highercomparison with the tabulated value (2.045) with a freedom degree (75) at a significance level (0.05). This shows that a statistically significant varianceis found between the meansof the two groupings in favor of the experimental grouping. Therefore, the first hypothesis is accepted.

\section{b. The Second Hypothesis}


Table 8: T-test findings for two interrelated specimens of the pre- and post-testsof the acquisition of concepts for the experimental grouping

\begin{tabular}{|c|c|c|c|c|c|c|c|}
\hline \multirow[t]{2}{*}{ Test } & \multirow[t]{2}{*}{ Number } & \multirow[t]{2}{*}{ Arith. Mean } & \multirow[t]{2}{*}{ S.D } & \multirow{2}{*}{$\begin{array}{l}\text { Freedom } \\
\text { degree }\end{array}$} & \multicolumn{2}{|l|}{ T-value } & \multirow{2}{*}{$\begin{array}{l}\text { Significance } \\
\text { level }\end{array}$} \\
\hline & & & & & Determined & Tabulated & \\
\hline Post-test & 38 & 32.9474 & 0.22629 & \multirow[t]{2}{*}{74} & \multirow[t]{2}{*}{226.304} & \multirow[t]{2}{*}{2.045} & \multirow[t]{2}{*}{0.05} \\
\hline Pre-test & 39 & 17.8684 & 0.34257 & & & & \\
\hline
\end{tabular}

c. The Third Hypothesis

To provethis hypothesis, the T-Test was applied to two interrelated specimens to determine if there is an acquisition of syntactic concepts among students of the control grouping who were taught utilizing the conventional method. The arithmetic mean of the post-test was (18.0513) with a S.D of (0.22346) and that of the pre-test was (17.8205) with a S.D of (0.38878), as clarified in table (9).

Table 9: T-test findings for two interrelated specimens of the pre- and post-tests of the acquisition of concepts for the controlgrouping

\begin{tabular}{|c|c|c|c|c|c|c|c|}
\hline \multirow[t]{2}{*}{ Test } & \multirow[t]{2}{*}{ Number } & \multirow[t]{2}{*}{ Arith. Mean } & \multirow[t]{2}{*}{ S.D } & \multirow{2}{*}{$\begin{array}{l}\text { Freedom } \\
\text { degree }\end{array}$} & \multicolumn{2}{|l|}{ T-value } & \multirow{2}{*}{$\begin{array}{l}\text { Significance } \\
\text { level }\end{array}$} \\
\hline & & & & & Determined & Tabulated & \\
\hline Post-test & 38 & 18.0513 & 0.22346 & \multirow[t]{2}{*}{76} & \multirow[t]{2}{*}{1.688} & \multirow[t]{2}{*}{2.045} & \multirow[t]{2}{*}{0.05} \\
\hline Pre-test & 39 & 17.8205 & 0.38878 & & & & \\
\hline
\end{tabular}

1. The use of the Appleton model in teaching Arabic language due to its significance in the acquisition ofsyntactic concepts.

2. Call onthe continuing education centers in colleges to work on opening training courses for teachers to train them in teaching according to modern teaching models, including the Appleton model.

3. Call on the continuing education centers to develop a teaching manual that explains modern teaching methods, including the Appleton model.

\section{Suggestions}

In line with the findings of the current research, the authors suggest the next:

1. Conduct a study involving the effect of the Appleton model on other study subjects.

2. Conduct a comparative study between the Appleton model and other modern models to determine their effecton teaching Arabic language.

\section{References}

Abu Zeina, F. (2010). Development and teaching of school mathematics curricula, 1 st ed. Amman, Jordan: Wael Press for Publishing and Distribution.

Al-Assadi, S. \& Al-Massoudi, M. (2015). Modern strategies and methods of teaching in geography, 1st ed. Amman, Jordan: Safaa Press for Publishing and Distribution.
Table (8) indicates that the determined T-value (226.304) is highercomparison with the tabulated value (2.045) with afreedom degree (74) at a significance level (0.05). This means that there is a statisticallysignificant variance in favor of the posttest.Accordingly, the second hypothesis is accepted, indicatingthat the students of the experimental groupingacquired the syntactic concepts.
Table (9) demonstrates that the determined T-value (1.688) is lowercomparison with the tabulated value (2.045) with a freedom degree (76) at a significance level (0.05). Accordingly, the thirdhypothesis is accepted that no statistically significant varianceis found between the average scores of students of the controlgrouping in the preand post-test. This means that the students of the controlgroupingdid not acquire the syntactic concepts.

\section{Conclusions}

In accordance withfindings of thisinvestigation, the authorsconcluded the following:

1. The Appleton model showed a clear positive effect on the acquisition of syntactic concepts for the first-stage students in the Department of Industrial Management.

2. The steps of the model put students in an active and effective position through initiative, asking questions and exchanging ideas.

3. The Appleton model had an effect on the acquisition of syntactic concepts compared to the conventional method.

\section{Recommendations}

Depending onfindings of this investigation, the authorssuggested the following: 
Social Sciences, 3(2): 66-70.

Shnawa, J. \& Abdul-Ameer, A. (2018). The effect of the Appleton model in the achievement and deductive thinking among students in the second intermediate grade in history subject. Al-Qadissiya Journal of Arts and Educational Sciences, 18(2).

Zambrano, C. \& Noriega, R. (2011). Approaches to scaffolding in teaching mathematics in English with primary school students in Colombia. Latin American.

Zayer, S. (2014). Contemporary educational encyclopedia. Baghdad, Iraq: Nour al-Hassan Press.

Zaytoun, A. (2007). Constructive theory and science teaching strategies, 1st ed. Amman, Jordan: Al-Shorouk Press for Publishing and Distribution.
Al-Jubouri, F. (2001). The effect of the Bronze model on acquiring syntactic concepts among primary school students (unpublished Master thesis). Al Mustansiriyah University.

Al-Khalidi, S. (1993). Difficulties in teaching and studying rhetoric among students of the fifth preparatory grade from the point of view of teachers and students (unpublished Master thesis). Baghdad University.

Al-Lami, S. \& Amir, A. (2017). The effect of the Appleton model on acquiring syntactic concepts among students of the fourth preparatory grade. Journal of College of Basic Education for Arts and Humanities, (34).

Al-Matroudi, K. (2009). The extent to which sixth graders acquire the prescribed doctrinal concepts at Riyadh city. Journal of Reading and Knowledge, (98).

Al-Muhaysin, I. (2007). Teaching science: Origins and modernization, 2nd ed. Riyadh, Saudi Arabia: Al-Abekan for Publishing and Distribution.

Al-Suwaidi, D. (1992). The development of the meaning of some religious concepts among primary school pupils. Periodical of College of Education, 9, Qatar University, Qatar.

Al-Yamani, A. (2009). Strategies of learning and teaching, 1st ed. Amman, Jordan: ZamZam Publishers and Distributors.

Appleton, K. (1997). Analysis and description of students learning during science classes: A constructivist - based model. Journal of Research in Science Teaching, 34(3).

Attia, M. (2015). Constructivism and its applications: Modern strategies, 1st ed. Amman, Jordan: Safaa Press for Publishing and Distribution.

Az-Zubay, R. (2009). Building a program in the rhetoric syllabus at departments of Arabic language at the Colleges of Education in Baghdad in light of the objectives of the subject (unpublished $\mathrm{PhD}$ thesis). University of Baghdad.

CAlik, M. \& Pasayas, A. (June 2006). Constructivist-based model for the teaching of dissolution of gas in liquid. Asia-Pacific Forum on Science Learning and Teaching, (1).

Nwosu, B. \& Azih, N. (2011). Effects of instructional scaffolding on the achievement of male and female students in financial accounting in secondary schools in Abakaliki Urban of Ebonyi State, Nigeria. Journal of 